Case Report

\title{
Sclerosing Angiomatoid Nodular Transformation: Laparoscopic Splenectomy as Therapeutic and Diagnostic Approach at the Same Time
}

\author{
Calogero Cipolla $\mathbb{D}^{1},{ }^{1}$ Ada Maria Florena, ${ }^{2}$ Gabriella Ferrara, ${ }^{1}$ Riccardo Di Gregorio, ${ }^{1}$ \\ Elettra Unti, ${ }^{2}$ Antonino G. Giannone, ${ }^{2}$ Luigi A. Lazzaro, ${ }^{1}$ Giuseppa Graceffa, ${ }^{1}$ \\ and Gianni Pantuso ${ }^{1}$ \\ ${ }^{1}$ Department of Surgical, Oncological and Oral Sciences, Division of General and Oncological Surgery, University of Palermo, \\ Palermo, Italy \\ ${ }^{2}$ Department of Sciences for Promotion of Health and Mother and Child Care, Anatomic Pathology, University of Palermo, \\ Palermo, Italy \\ Correspondence should be addressed to Calogero Cipolla; calogero.cipolla@unipa.it
}

Received 7 December 2017; Accepted 22 March 2018; Published 8 May 2018

Academic Editor: Gaetano La Greca

Copyright (c) 2018 Calogero Cipolla et al. This is an open access article distributed under the Creative Commons Attribution License, which permits unrestricted use, distribution, and reproduction in any medium, provided the original work is properly cited.

\begin{abstract}
Introduction. Sclerosing angiomatoid nodular transformation (SANT) of the spleen is a rare benign vascular lesion with unknown etiopathogenesis and with definite features of imaging, histopathology, and immunohistochemistry. It was first described by Martel et al. in 2004, and to date, only 151 cases have been reported. Case Description. We report a case of SANT of the spleen detected in a 66-year-old Caucasian, without comorbidities, presented to our department with epigastric pain. We, also, presented a review of the literature. Conclusions. SANT is a benign incidentally vascular condition in the majority of cases. The wide age and gender distribution in our review is in accordance with that in previous studies in English literature. In our opinion, splenectomy is the choice treatment because it is at the same time diagnostic and therapeutic in a definitive way.
\end{abstract}

\section{Introduction}

Sclerosing angiomatoid nodular transformation (SANT) of the spleen is a rare benign vascular lesion with unknown etiopathogenesis and with definite features of imaging, histopathology, and immunohistochemistry. It was first described by Martel et al. in 2004 [1], and to date, only 151 cases have been reported.

However, real incidence and prevalence are still unknown. In this paper, we report a case of SANT of the spleen managed in our institute and we present a review of the literature.

\section{Case Report}

A 66-year-old Caucasian woman, without comorbidities, presented to our department with epigastric pain. Abdominal examination did not evidence any other clinical signs. Hematological parameters reported an increase in PCR values, with no other pathological findings. The abdominal ultrasonography demonstrated a regular hypoechoic nodular formation at the lower pole of the spleen with an $8 \mathrm{~cm}$ maximum diameter, with calcification spot. Computed tomography scan confirmed the hypodense lesion presence, with a $77 \mathrm{~mm}$ maximum diameter, and calcifications in the context 


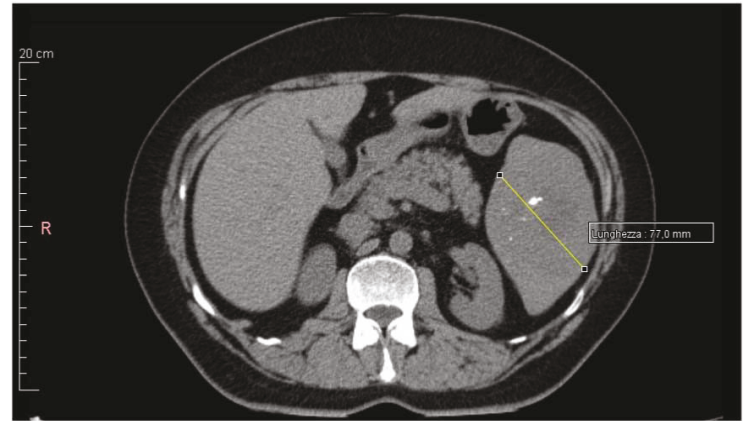

(a)

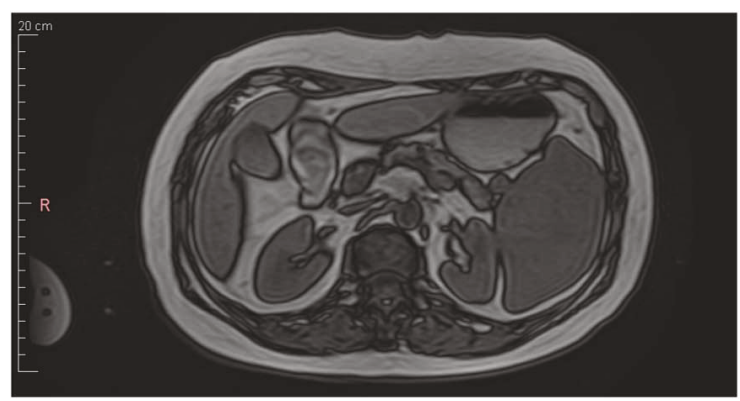

(c)

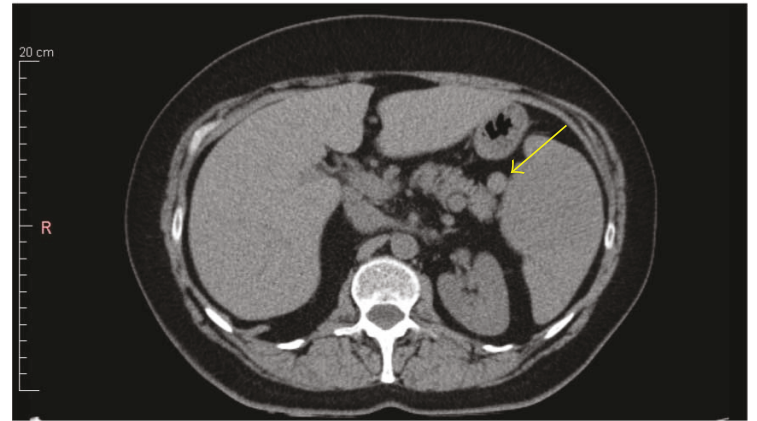

(b)

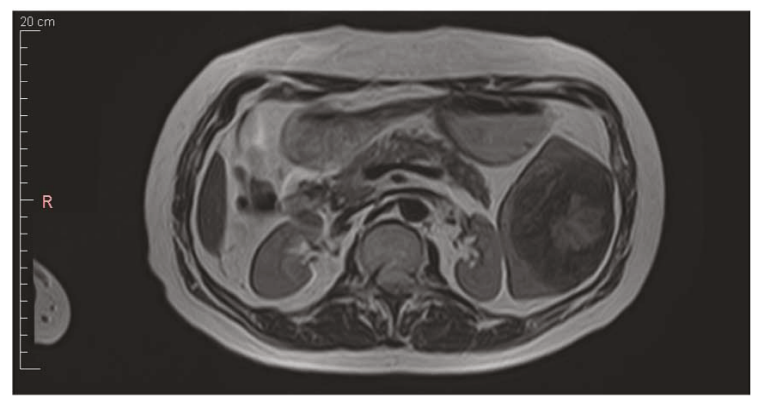

(d)

FIGURE 1: SANT on the imaging. (a) CT: hypodense lesion with a $77 \mathrm{~mm}$ maximum diameter and calcifications in the context. (b) CT: centimetric accessory spleen. (c) MRI: lesion $(6.3 \mathrm{~cm} \times 8.2 \mathrm{~cm})$ characterized by heterogeneous intensity, iso-hypointense in T1. (d) MRI: a signal hypointense of the lesion in T2 with a centrally scattered hyperintense signal on the fat saturated precontrast phase.

(Figure 1(a)). In addition, a centimetric accessory spleen adjacent to the lower pole was detected (Figure 1(b)). MRI study showed a massive lesion $(6.3 \mathrm{~cm} \times 8.2 \mathrm{~cm})$ characterized by heterogeneous intensity, iso-hypointense in $\mathrm{T} 1$ (Figure 1(c)), predominantly hypointense in T2 with a centrally scattered hyperintense signal on the fat saturated precontrast phase (Figure1(d)). The early arterial phase evidenced peripheral enhancement with central radial progression, on the late phase images.

We decided to proceed with surgical therapy, without making a spleen biopsy, and we opted for a laparoscopic splenectomy, because of diagnostic uncertainty due to unspecific features of imaging not excluding the malignant lesion nature. During abdominal cavity exploration, we identified the mass at the lower pole of the spleen (Figure 2). The spleen was completely placed in a specific bag, and, after centimetric accessory spleen removal, we sent it to the Department of Pathology of our hospital structure for histological examination. The postsurgery period had normal results except for a single episode of atrial fibrillation. We also administered a pneumococcal vaccine to prevent any postsplenectomy infections and discharged the patient 8 days after the surgery without any complications.

\section{Pathologic Findings}

The spleen measured $12.5 \times 10 \times 7 \mathrm{~cm}$ and weighted $480 \mathrm{~g}$; the lower pole was occupied by an unencapsulated nodular lesion, $7 \times 7.2 \times 6 \mathrm{~cm}$, with multilobular architecture and well-defined and stellate edges with infiltrative margins.
The lesion was firm, with grayish to white-tan color (Figure 3(a)). On low magnification, histologic sections showed vascular nodules of variable sizes, sometimes coalescent, surrounded by a rim of concentric fibrous tissue (Figure 3(b)). The vascular component within nodules was composed by variably sized blood vessels, with slit-like, round, or irregular shape (Figure 3(c)). The vascular spaces were lined by plump endothelial cells with occasional spindle or ovoid cells. Nuclear atypia was absent; mitotic figures were inconspicuous (<1/50 HPF). The internodular tissue consisted of dense fibrous tissue with myxoid areas and scattered plump myofibroblasts, plasma cells, lymphocytes, and siderophages (Figure $3(\mathrm{~d})$ ). The surrounding splenic parenchyma showed prominent vascular congestion and blood extravasation. Blood vessels within the lesion showed three main immunophenotypes: CD34+/CD8-/CD31+ capillaries, CD34-/CD8+/CD31+ sinusoids, and CD34-/CD8-/CD31+ small veins (Figure 4). The proliferation index, assessed with Ki67, was lower than 2\%. Plasma cells were positive for CD138 with polytypic expression of $\mathrm{m}$ and 1 light chains but were negative for IgG4. CD68 highlighted siderophages and sinusoidal macrophages. The immunohistochemical stains for HHV8, EBV-LMP1, and ALK1 were negative. All these features were consistent with sclerosing angiomatoid nodular transformation of the spleen.

\section{Discussion}

SANT of the spleen first described by Martel et al. [1] in 2004. They exposed a series of 25 patients who presented the same 


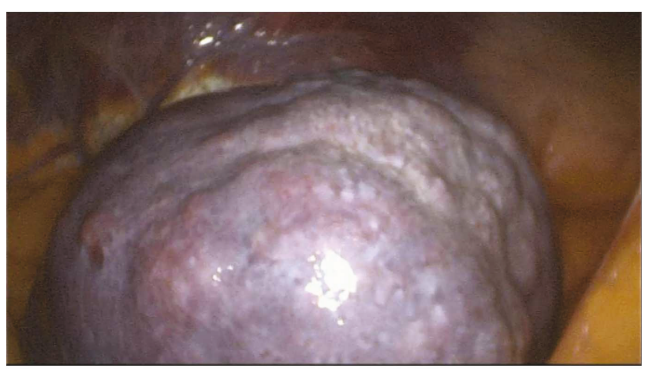

(a)

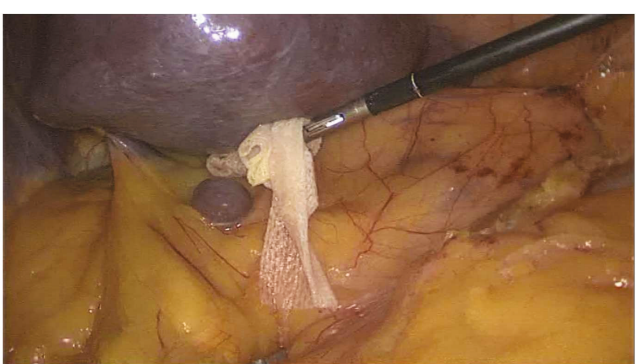

(b)

Figure 2: Laparoscopic view of the spleen. (a) The mass at the lower pole of the spleen. (b) Accessory spleen.

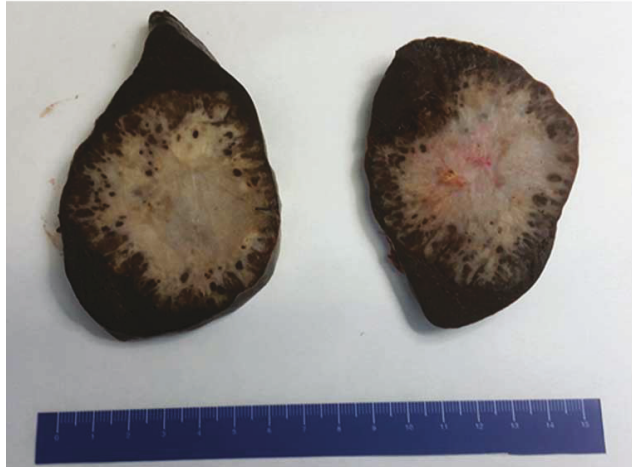

(a)

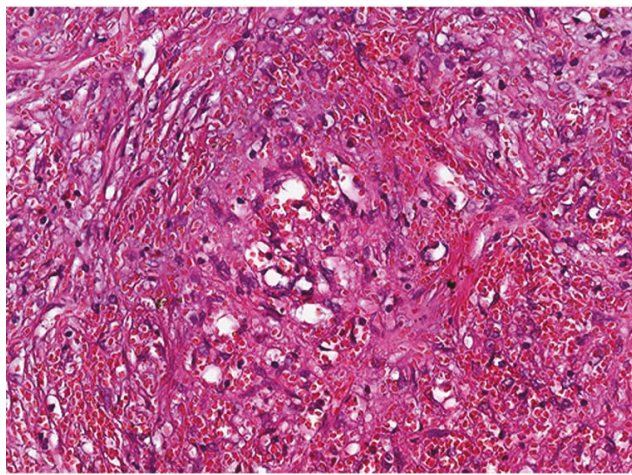

(c)

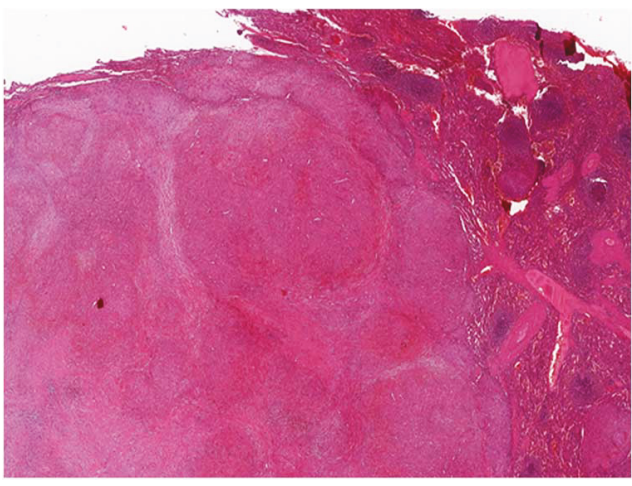

(b)

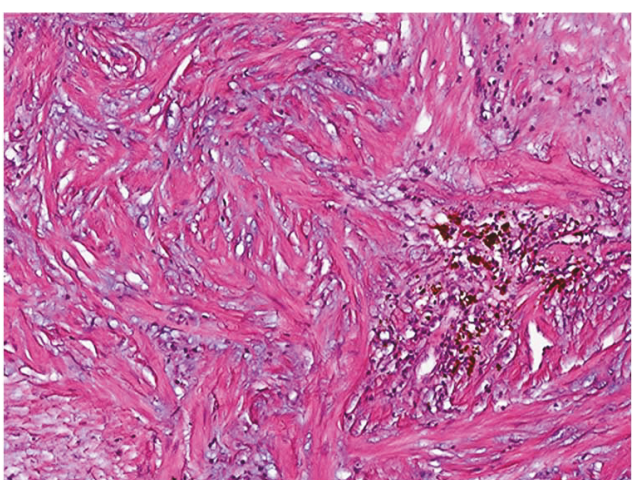

(d)

Figure 3: Histopathological findings. (a) On gross examination, the cut surface shows a solitary, well-circumscribed but unencapsulated lesion; at the periphery, multiple dark-brown nodules are interspersed with the fibrotic stroma. (b) At low magnification, the lesion consisted of multiple angiomatoid nodules in a fibrotic stroma, with sharp demarcation from the adjacent splenic parenchyma (right). (c) Vascular component within nodules composed by small-sized blood vessels, with slit-like, round, or irregular shape; an incomplete fibrinoid rim was present at the periphery of this angiomatoid nodule. (d) The internodular tissue consisted of dense fibrous tissue with myxoid areas with siderophages and scattered plump myofibroblasts, plasma cells, and lymphocytes. Original magnifications-b: $\times 10$; c and $d: \times 200$.

clinical, imaging, histopathology, and immunohistochemistry features. In this paper, we reported a case of SANT cured in our surgical unit and reviewed retrospectively clinical cases of 151 patients in English literature, starting with the 128 cases reported by Cao et al. [1-3] in 2015 and expanding this research with 23 cases reported in other studies from October 2011 to the present (Table 1).

In this study, we reported a total of 152 cases of SANT (including this case) that included 73 males $(48.02 \%)$ and 79 females (51.97\%). The age range is 3 to 82 years old, with a mean age of 45 (45.44) years which is a little bit inferior to the data reported by Cao et al. [3]. The ratio of male to female was $1: 1.08$, with an incidence generally comparable between both genders according to the previous analysis.

Our case could be added to the 144 cases of solitary SANT already described in literature, whereas only 7 cases were multifocal SANT [3-5]. In our review of the cases in English literature, 109 of these 151 cases (72.18\%) did not present any clinical symptoms and accidentally discovered the lesion during imaging controls. In the remaining patients, 


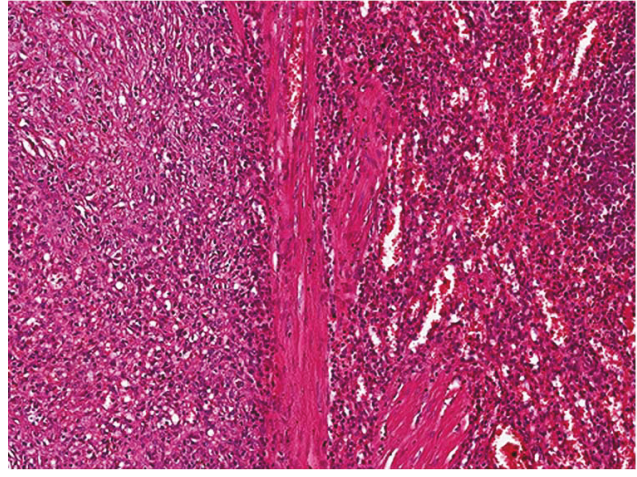

(a)

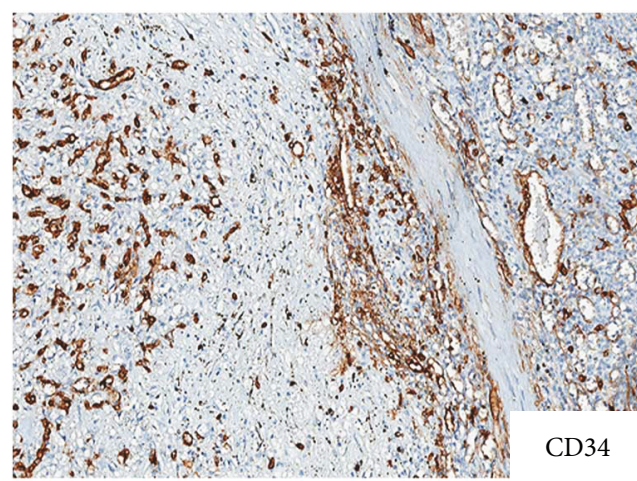

(c)

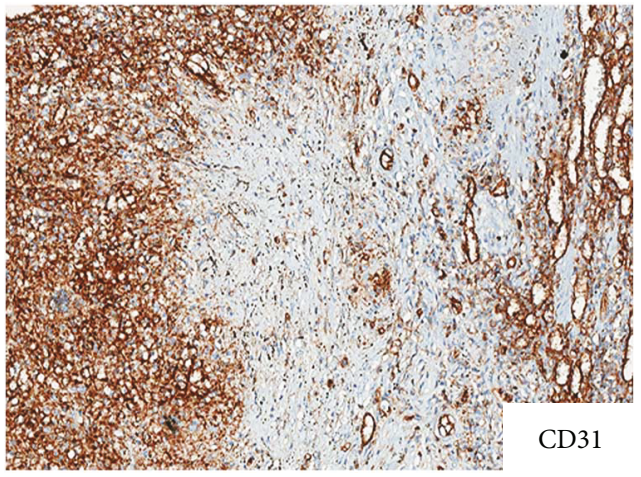

(b)

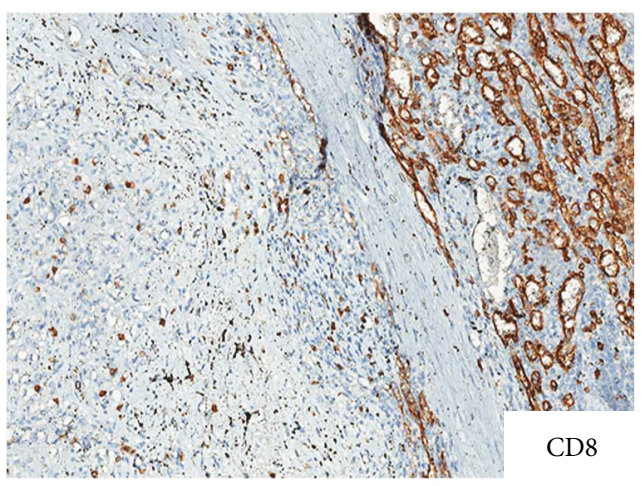

(d)

Figure 4: Comparison of the lesion ( $a, c)$ with the adjacent spleen parenchyma $(b, d)$. The overall phenotype of lesional vessels differed from that of spleen parenchyma. The blood vessels within the lesion showed three main immunophenotypes: CD34+/CD8-/CD31+ capillaries, CD34-/CD8-/CD31+ small veins, and rarer CD34-/CD8+/CD31+ sinusoids. Original magnifications-a-d: $\times 100$.

the main symptom was abdominal pain $(n=39)$. Other symptoms were a palpable abdominal mass, cytopenias, flank pain, pelvic pain, fever, nosebleed and anemia [6,7], vomiting, pruritus in the lower limbs [8], and weight loss [9]. There were two reported deaths in the Martel's cases [1]: a 56-yearold woman who died of disseminated lung adenocarcinoma and a 46-year-old man with concurrent bronchogenic squamous cell carcinoma who died of sepsis post splenectomy. In our case, abdominal MRI excluded a concomitant neoplasm and pneumococcal vaccination was used to reduce the risk of infection. Currently, pathognomonic detection for the imaging diagnosis of SANT does not exist [10]. The general features are peripheral enhancing radiating lines and rim enhancement of the lesions evaluated with contrast-enhanced CT or MRI during the arterial or portal venous phases. Gutzeit et al. [11] referred to this pattern of enhancement as a "spoke wheel" appearance on contrastenhanced ultrasound, CT, and MRI. Furthermore, Gutzeit proposed the use of contrast-enhanced ultrasonography to diagnose SANT, but there are still a few studies about it. SANT must be histologically distinguished from inflammatory pseudotumor (IP), hamartomas, and the vascular proliferations of the spleen, such as littoral cell angioma, capillary and venous hemangioma, hemangioendothelioma, lymphangioma, angiosarcoma, and nodular transformation of the splenic red pulp [12] (desmoplastic response to metastatic carcinoma). IP represents one of the main differential diagnosis; the two lesions can often share some architectural similarities, especially in the stromal component, but the lack of multinodular architecture, together with the negativity for ALK1, can aid to rule out the diagnosis of IP [4]. Splenic hamartoma [13] is a tumor-like lesion composed of red pulp elements with disordered architecture, without the typical angiomatoid multinodular structure, observed in SANT. Moreover, the phenotype of blood vessels in splenic hamartoma differs from SANT. The vascular spaces of SANT comprise various nature vessels (capillary, sinusoids, and veins) with a specific phenotype; on the opposite, vascular tumors show vessels with a monotonous phenotype, with variable features of malignancy, ranging from hemangioma [14] and lymphangioma to hemangioendothelioma and angiosarcoma. Although rare, SANT is a diagnostic entity to be taken into account among splenic nodular lesions, with wellestablished diagnostic features. According to recent studies, percutaneous image-guided CNB of the spleen is becoming safe and effective in tissue diagnosis results [6]. There is a debate about whether an asymptomatic patient should be subjected to a surgical procedure to obtain diagnosis. Most of the published cases get to the diagnosis after splenectomy. Despite that Weinreb et al. [15] suggest that good core biopsy can be used to distinguish SANT from other lesions, splenic biopsy has been employed rarely (only 2 to 23 cases in Table 1 ). Anyway, there is a significant intraperitoneal $[6,15]$ dissemination risk if the biopsied lesion proves to be angiosarcoma and have other complications (splenic rupture and bleeding). The etiopathogenesis 


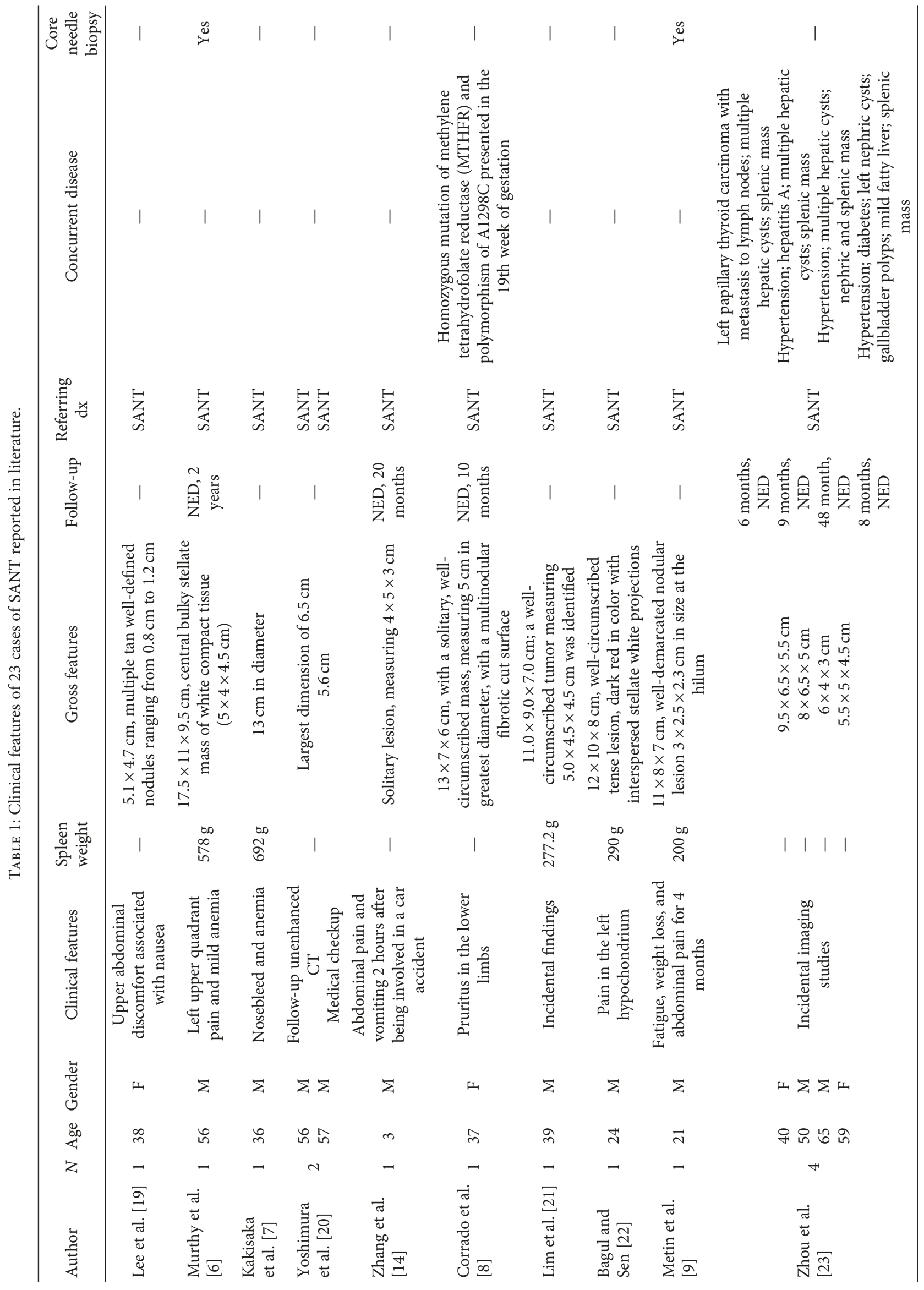




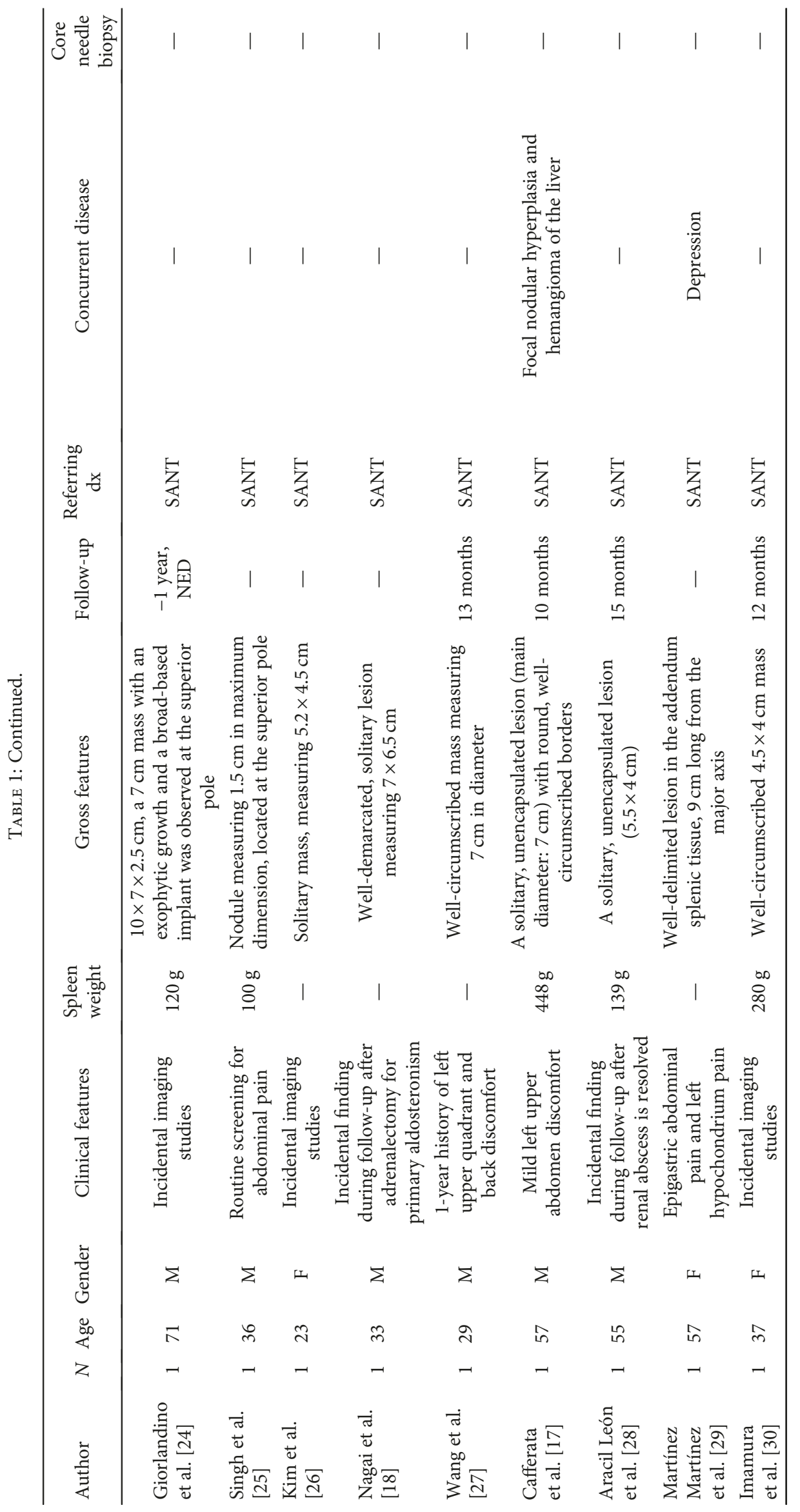


is still unknown, but several causes are hypothesized: Epstein-Barr virus association [16], red pulp abnormal transformation due to stromal proliferation, or hamartomas/ inflammatory pseudoneoplasm final stage $[6,17]$. Finally, in recent studies [18], it is noted that SANT proliferation could be associated to the typical sclerosing injuries of the disorder related to immunoglobulin G4 (IgG4).

SANT is a benign incidentally vascular condition in the majority of cases. The wide age and gender distribution in our review is in accordance with the previous studies in English literature. In our opinion, splenectomy is the choice treatment because it is at the same time diagnostic and therapeutic in a definitive way.

\section{Consent}

Informed consent was obtained from the individual described in this report.

\section{Conflicts of Interest}

The authors declare that there is no conflict of interest regarding the publication of this article.

\section{References}

[1] M. Martel, W. Cheuk, L. Lombardi, B. Lifschitz-Mercer, J. K. C. Chan, and J. Rosai, "Sclerosing angiomatoid nodular transformation (SANT): report of 25 cases of a distinctive benign splenic lesion," The American Journal of Surgical Pathology, vol. 28, no. 10, pp. 1268-1279, 2004.

[2] G. A. Falk, N. P. Nooli, G. Morris-Stiff, T. P. Plesec, and S. Rosenblatt, "Sclerosing angiomatoid nodular transformation (SANT) of the spleen: case report and review of the literature," International Journal of Surgery Case Reports, vol. 3, no. 10, pp. 492-500, 2012.

[3] Z. Cao, Q. Wang, J. Li, J. Xu, and J. Li, "Multifocal sclerosing angiomatoid nodular transformation of the spleen: a case report and review of literature," Diagnostic Pathology, vol. 10, no. 1, p. 95, 2015.

[4] J. Diebold, A. Le Tourneau, B. Marmey et al., "Is sclerosing angiomatoid nodular transformation (SANT) of the splenic red pulp identical to inflammatory pseudotumour? Report of 16 cases," Histopathology, vol. 53, no. 3, pp. 299-310, 2008.

[5] J. C. Lee, H. C. Lien, and C. H. Hsiao, "Coexisting sclerosing angiomatoid nodular transformation of the spleen with multiple calcifying fibrous pseudotumors in a patient," Journal of the Formosan Medical Association, vol. 106, no. 3, pp. 234239, 2007.

[6] V. Murthy, B. Miller, E. M. Nikolousis, G. Pratt, and Z. Rudzki, "Sclerosing angiomatoid nodular transformation of the spleen," Clinical Case Reports, vol. 3, no. 10, pp. 888-890, 2015.

[7] T. Kakisaka, T. Kamiyama, H. Yokoo et al., "Hand-assisted laparoscopic splenectomy for sclerosing angiomatoid nodular transformation of the spleen complicated by chronic disseminated intravascular coagulation: a case report," Asian Journal of Endoscopic Surgery, vol. 7, no. 3, pp. 275-278, 2014.

[8] G. Corrado, V. Tabanelli, R. Biff, G. Petralia, A. Tinelli, and F. A. Peccatori, "Sclerosing angiomatoid nodular transformation of the spleen during pregnancy: diagnostic challenges and clinical management," Journal of Obstetrics and Gynaecology Research, vol. 42, no. 8, pp. 1021-1025, 2016.

[9] M. R. Metin, Ş. Evrimler, N. Çay, and H. Çetin, “An unusual case of sclerosing angiomatoid nodular transformation: radiological and histopathological analyses," Turkish Journal of Medical Sciences, vol. 44, no. 3, pp. 530-533, 2014.

[10] C. Thacker, R. Korn, J. Millstine, H. Harvin, J. A. Van Lier Ribbink, and M. B. Gotway, "Sclerosing angiomatoid nodular transformation of the spleen: CT, MR, PET, and ${ }^{99 \mathrm{~m}} \mathrm{Tc}$-sulfur colloid SPECT CT findings with gross and histopathological correlation," Abdominal Imaging, vol. 35, no. 6, pp. 683-689, 2010.

[11] A. Gutzeit, G. Stuckmann, and C. Dommann-Scherrer, "Sclerosing angiomatoid nodular transformation (SANT) of the spleen: sonographic finding," Journal of Clinical Ultrasound, vol. 37, no. 5, pp. 308-311, 2009.

[12] A. A. Awamleh and B. Perez-Ordoñez, "Sclerosing angiomatoid nodular transformation of the spleen," Archives of Pathology \& Laboratory Medicine, vol. 131, no. 6, pp. 974978, 2007.

[13] J. Szpor and G. Dyduch, "From hamartoma to splenic hemangioma," Polish Journal of Pathology, vol. 59, no. 1, pp. 33-41, 2008.

[14] S. Zhang, W. Yang, H. Xu, and Z. Wu, "Sclerosing angiomatoid nodular transformation of spleen in a 3-year-old child," Indian Pediatrics, vol. 52, no. 12, pp. 1081-1083, 2015.

[15] I. Weinreb, D. Bailey, D. Battaglia, M. Kennedy, and B. PerezOrdoñez, "CD30 and Epstein-Barr virus RNA expression in sclerosing angiomatoid nodular transformation of spleen," Virchows Archiv, vol. 451, no. 1, pp. 73-79, 2007.

[16] A. Di Blasi, A. Boscaino, G. De Dominicis, and G. MarinoMarsilia, "Splenic hamartoma," Pathologica, vol. 97, no. 3, pp. 124-129, 2005.

[17] B. Cafferata, M. Pizzi, F. D’Amico, C. Mescoli, and R. Alaggio, "Sclerosing Angiomatoid nodular transformation of the spleen, focal nodular hyperplasia and hemangioma of the liver: a tale of three lesions," Pathology - Research and Practice, vol. 212, no. 9, pp. 855-858, 2016.

[18] Y. Nagai, D. Satoh, H. Matsukawa, and S. Shiozaki, "Sclerosing angiomatoid nodular transformation of the spleen presenting rapid growth after adrenalectomy: report of a case," International Journal of Surgery Case Reports, vol. 30, pp. 108-111, 2017.

[19] M. Lee, M. Caserta, and H. Tchelepi, "Sclerosing angiomatoid nodular transformation of the spleen," Ultrasound Quarterly, vol. 30, no. 3, pp. 241-243, 2014.

[20] N. Yoshimura, K. Saito, N. Shirota et al., "Two cases of sclerosing angiomatoid nodular transformation of the spleen with gradual growth: usefulness of diffusion-weighted imaging," Clinical Imaging, vol. 39, no. 2, pp. 315-317, 2015.

[21] H. T. Lim, C. H. Tan, L. T. Teo, and C. S. Ho, "Multimodality imaging of splenic sclerosing angiomatoid nodular transformation," Singapore Medical Journal, vol. 56, no. 6, pp. e96e99, 2015.

[22] K. A. Bagul and A. Sen, "Sclerosing angiomatoid nodular transformation of spleen masquerading as a splenic abscess," Indian Journal of Pathology and Microbiology, vol. 58, no. 3, pp. 359-361, 2015.

[23] J. Zhou, D. Zhang, G. Hu et al., "Upregulated expression of CD30 protein in sclerosing angiomatoid nodular transformation (SANT): studies of additional 4 cases and analyses of 6 
cases previously published cases," International Journal of Clinical and Experimental Pathology, vol. 8, no. 6, pp. 60646069, 2015.

[24] A. Giorlandino, R. Caltabiano, and S. Lanzafame, "A case of sclerosing angiomatoid nodular transformation of the spleen," Pathologica, vol. 105, no. 3, pp. 94-97, 2013.

[25] N. Singh and J. S. Chauhan, "Sclerosing angiomatoid nodular transformation of the spleen: a case report," International Journal of All Research Education and Scientific Methods (IJARESM), vol. 8, no. 3, pp. 4-7, 2015.

[26] K.-H. Kim, S. Lee, S. H. Youn et al., "Laparoscopic splenectomy for sclerosing angiomatoid nodular transformation of the spleen," Journal of the Korean Surgical Society, vol. 80, Supplement 1, pp. S59-S62, 2011.

[27] T.-B. Wang, B.-G. Hu, D.-W. Liu, Z.-H. Gao, H.-P. Shi, and W.-G. Dong, "Sclerosing angiomatoid nodular transformation of the spleen: a case report and literature review," Oncology Letters, vol. 12, no. 2, pp. 928-932, 2016.

[28] E. Aracil León, C. Olona Casas, M. R. Taco Sánchez, and A. Raventós Estellé, "Transformación nodular angiomatoide esclerosante (SANT) del bazo. Presentación de un caso y revisión de la literatura," Revista Española de Patología, vol. 49, no. 1, pp. 45-49, 2016.

[29] P. J. Martínez Martínez, R. Solbes Vila, C. J. Bosquet Úbeda, and J. M. Roig Álvaro, "Sclerosing angiomatoid nodular transformation of the spleen. A case report," Revista Española de Enfermedades Digestivas, vol. 109, no. 3, pp. 214-215, 2017.

[30] Y. Imamura, R. Nakajima, K. Hatta et al., "Sclerosing angiomatoid nodular transformation (SANT) of the spleen: a case report with FDG-PET findings and literature review," Acta Radiologica Open, vol. 5, no. 8, 2016. 


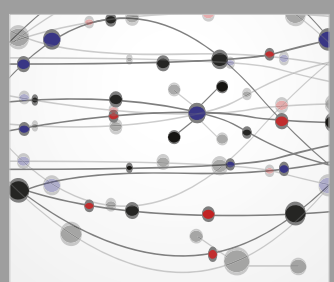

The Scientific World Journal
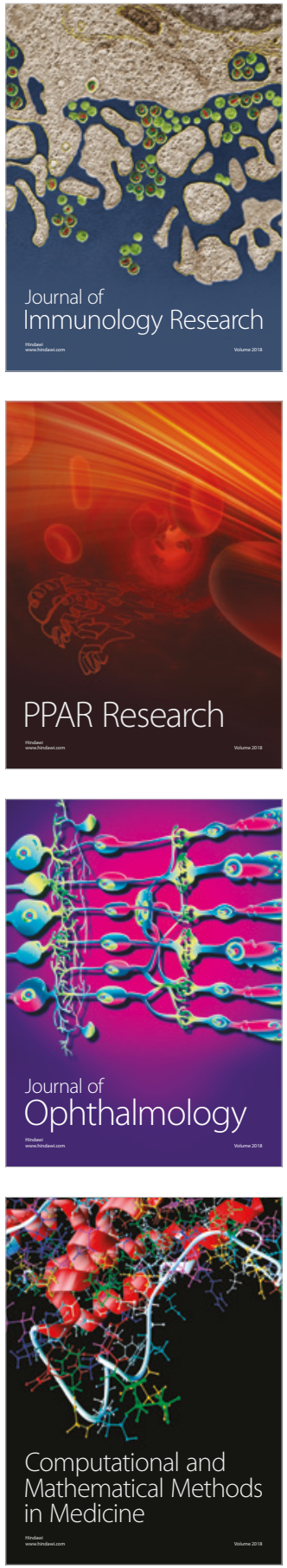

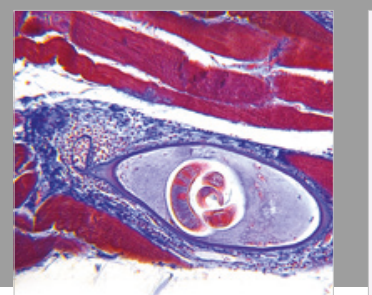

Gastroenterology Research and Practice

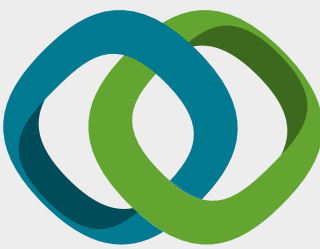

\section{Hindawi}

Submit your manuscripts at

www.hindawi.com
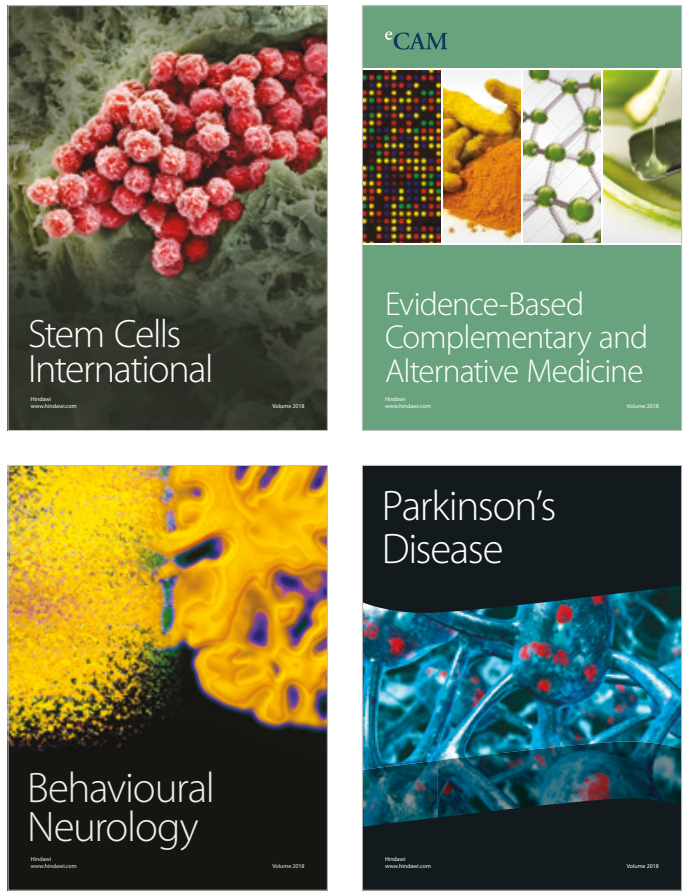

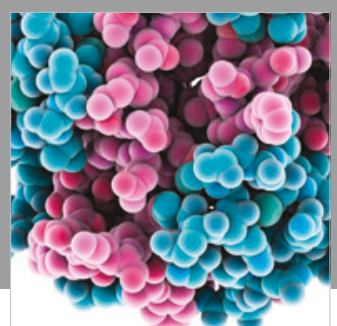

ournal of

Diabetes Research

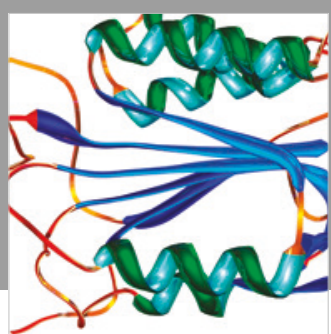

Disease Markers
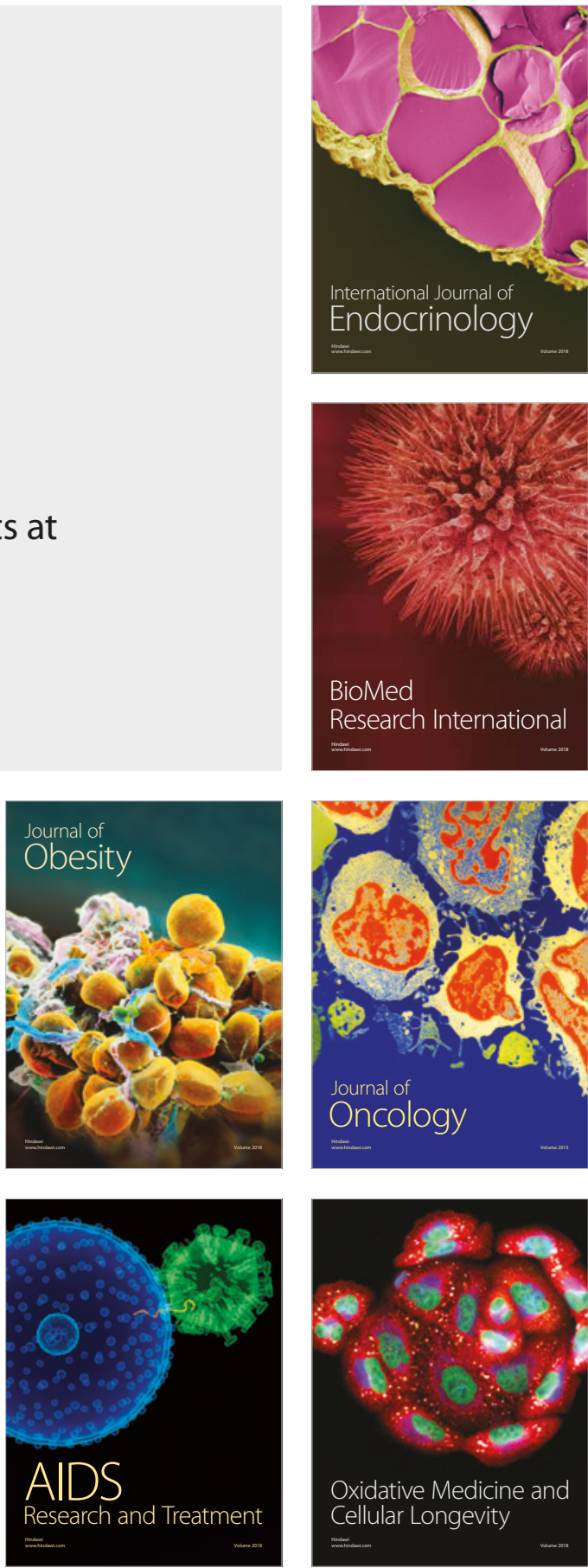